Classification

Physics Abstracts

61.16Di $-73.40 \mathrm{Ns}$

\title{
S.T.M. studies on semiconductor surfaces and metal- semiconductor interfaces
}

\author{
Frank Palmino $\left({ }^{1}\right)$, Philippe Dumas $\left({ }^{1}\right)$, Frank Thibaudau $\left({ }^{2}\right)$, Philippe Mathiez $\left({ }^{1}\right)$, \\ Christian Mouttet $\left({ }^{1}\right)$ and Frank Salvan $\left({ }^{1}\right)$
}

(1) Groupe de Physique des Etats Condensés, URA CNRS 783, Faculté des Sciences de Luminy, Département de Physique, Case 901, 13288 Marseille Cedex 9, France

$\left({ }^{2}\right)$ C.E.N. Saclay, DPHG-PAS, Bât. 462, 91191 Gif/Yvette, France

(Received October 01, 1990; accepted January 15, 1991)

\begin{abstract}
Résumé. - Au cours des dernières années, la caractérisation en microscopie tunnel des surfaces à l'échelle nanométrique a permis une meilleure compréhension de leurs propriétés structurales et électroniques. Cet article fait état d'expériences de microscopie par effet tunnel sur des surfaces de silicium et sur des interfaces métal-silicium que nous avons effectuées dans notre groupe à Marseille. Nous discuterons les systèmes suivants : $\mathrm{Si}(111) ; \mathrm{B}-\mathrm{Si}(111) \sqrt{3} \times \sqrt{3} \mathrm{R}\left(30^{\circ}\right) ; \mathrm{Sn} / \mathrm{Si} \sqrt{3} \times \sqrt{3} \mathrm{R}\left(30^{\circ}\right)$ et $\mathrm{Ag} / \mathrm{Si}(111)$. L'obtention de la résolution atomique a été, depuis l'invention de la microscopie tunnel, la principale préoccupation dans l'étude des propriétés structurales des surfaces. Nous mettons ici l'accent sur la nécéssité d'avoir également une information sur la topographie de la surface à plus grande échelle. Ce type de microscopie tunnel a récemment été utilisé par notre groupe et nous a permis de relier la rugosité de la surface de silicium (111) à la méthode de préparation des échantillons.
\end{abstract}

\begin{abstract}
In the last few years, a better understanding of the structural and electronic properties of surfaces at the nanometric scale has been achieved via S.T.M. characterisation. The aim of this paper is to report on surface physics experiments on Si surfaces and metal-silicon interfaces which have been carried out in our S.T.M. group in Marseille. The following systems will be discussed: $\mathrm{Si}$ (111); B/Si (111) $\sqrt{3} \times \sqrt{3} \mathrm{R}\left(30^{\circ}\right) ; \mathrm{Sn} / \mathrm{Si}$ (111) $\sqrt{3} \times \sqrt{3} \mathrm{R}\left(30^{\circ}\right) ; \mathrm{Ag} / \mathrm{Si}$ (111). Whereas achieving atomic resolution in structural studies of surfaces has long been the major goal since early S.T.M. work, we insist on the necessity of having in parallel an overview of the topography of the surface on rather large scan-windows. This kind of microscopy using S.T.M. has recently received attention on our group and allowed us to correlate the corrugation of the surface with the preparation procedure.
\end{abstract}

\section{Introduction.}

Following the development of STM by Binnig and Rohrer [1] in the early eighties, new insights on the structural and electronic properties of surfaces at a nanometric scale have been obtained. 
The aim of this paper in the frame of this Swedish-French Colloquium is to report on surface physics experiments on Si surfaces and metal silicon interfaces which have been carried out in our STM group in Marseille in the last few years. We have been interested in the properties of ordered substrates as well as in the early stages of metal semiconductor interfaces as probed by classical surface sensitive techniques (Auger, LEED) and Scanning Tunneling Microscopy.

This paper is organized as follows:

After the description of the experimental set-up, we present data on a new interesting system, B/Si (111) $\sqrt{3}$, which was studied for the first time using S.T.M. in our lab.

We then report data on $\mathrm{Sn} / \mathrm{Si}(111) \sqrt{3}$ structure and stress on the necessity of using scanwindows large enough to get an overall view of the surface topography. This systematic approach is then used for the characterization of Si(111) surface via S.T.M.

Preliminary results on local photon emission mapping [2] on the Ag/Si system are also discussed.

\section{Experimental}

All the experiments are performed in UHV conditions (basis pressure $2 \times 10^{-10}$ Torr) and a schematic diagram of our experimental set-up is shown in figure 1 . The samples are introduced from the atmosphere via an air-lock system and transferred to a preparation chamber equipped with LEED, Auger and metal evaporation facilities.

The surface preparation of the Si samples is made by direct heating at $1100^{\circ} \mathrm{C}$ after carefully disgasing the samples at $600^{\circ} \mathrm{C}$.

Cleanliness of the sample is checked by Auger and atomic ordering by means of LEED. The initial substrate before metal deposition is generally a $7 \times 7$ reconstructed $\mathrm{Si}(111)$ surface. However, in the case of highly p-doped samples with boron, boron atoms induced a $\sqrt{3} \times \sqrt{3} \mathrm{R}\left(30^{\circ}\right)$ reconstruction which has been the object of careful investigations.

Our S.T.M. is a pocket-size version which was designed in IBM Zürich laboratories. Data acquisition is controlled by a PC AT and images are presented in top view grey tone representation of the surface or 3D images. The number of pixels for one image is $(256) \times(256)$ and the resolution obtained depends on the piezo scan amplitude. Atomic resolution can be obtained using scan window of the order of $30 \mathrm{~nm} \times 30 \mathrm{~nm}$ on a very localized part of the surface. Overall topography can be understood by comparing several scan windows of $\sim 500 \mathrm{~nm} \times 500 \mathrm{~nm}$ with a lateral resolution of a few nm.

Since many papers have been devoted to the structural and electronic properties of the $7 \times 7$ reconstruction, I'll rather describe here a recent system which was studied with S.T.M. for the first time in our lab [3]. This is namely the $\mathrm{B} / \mathrm{Si}(111) \sqrt{3} \times \sqrt{3} \mathrm{R}\left(30^{\circ}\right)$.

$\mathrm{B} / \mathrm{Si}(111)$. - This boron induced reconstruction is obtained by annealing around $1000^{\circ} \mathrm{C} \mathrm{a}$ boron doped Si sample ( $\sim 1 \mathrm{~m} \Omega \mathrm{cm}$ - conductivity) either by a series of flashes or by long time annealing. After the annealing procedure, a sharp $\sqrt{3} \times \sqrt{3}$ pattern $30^{\circ}$ rotated from the $1 \times 1 \mathrm{Si}$ pattern is obtained. A real space 3D image of this $\sqrt{3}$ reconstruction is shown in figure 2 , where the bumps $6.7 \AA$ apart correspond to Si adatoms.

Comparing images obtained at opposite polarities on the same area allowed us to probe simultaneously empty and filled surface electronic states. A structural model for the boron atom position has been proposed where the boron atoms are located in the second layer of Si atoms in a substitutional site [3]. This position of the boron atoms in subsurface has been confirmed by different authors [4] using different techniques.

This is an unexpected situation as compared the $\sqrt{3}$ reconstruction obtained with other group III élement $\mathrm{M}$ ( $\mathrm{Al}, \mathrm{In}, \mathrm{Ga}$ ) where the $\mathrm{M}$ atoms sit in adatom positions. It is in fact a consequence of the small atom radius of boron which prevents a stable configuration of $\mathrm{B}$ atoms sitting in 


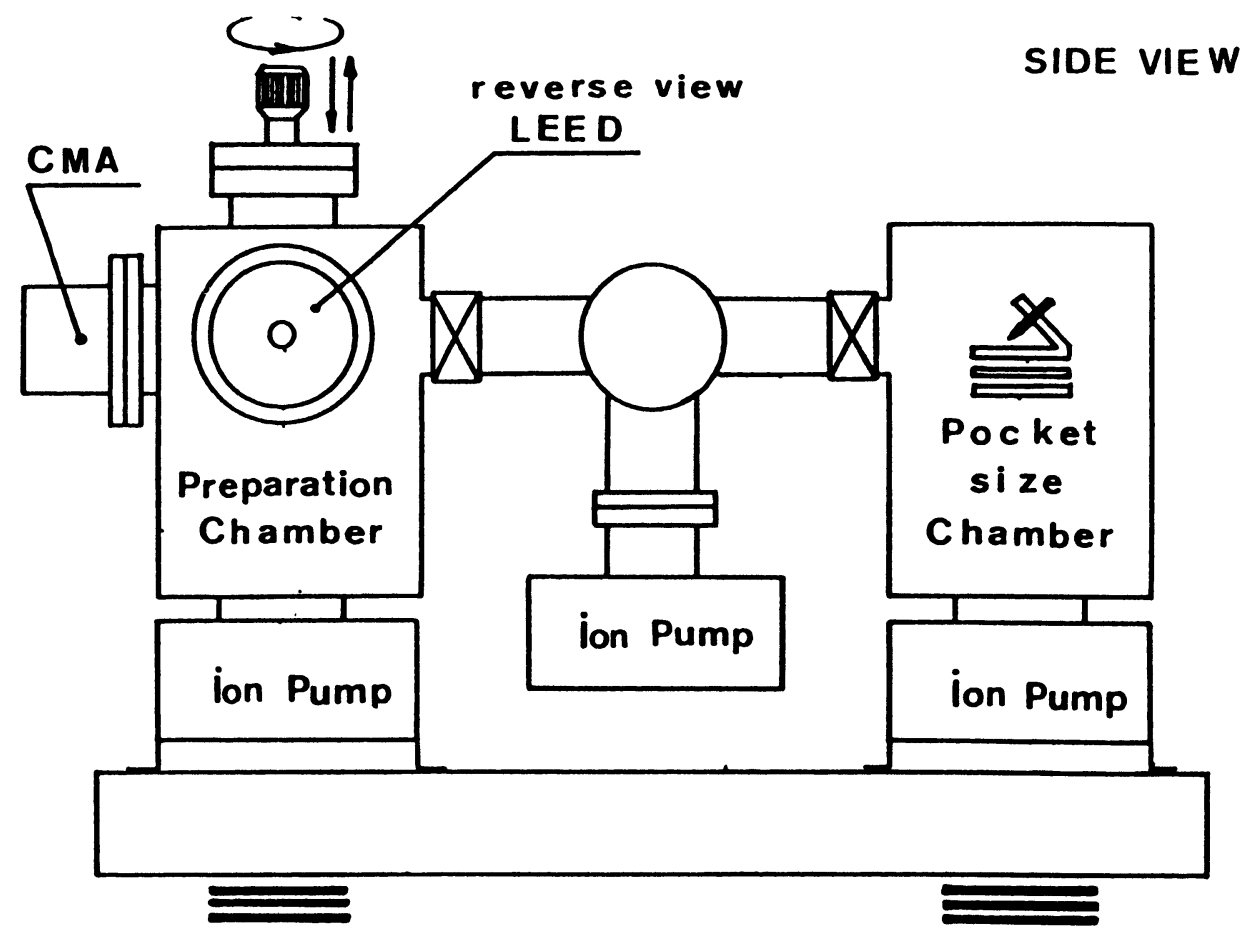

TOP VIEW

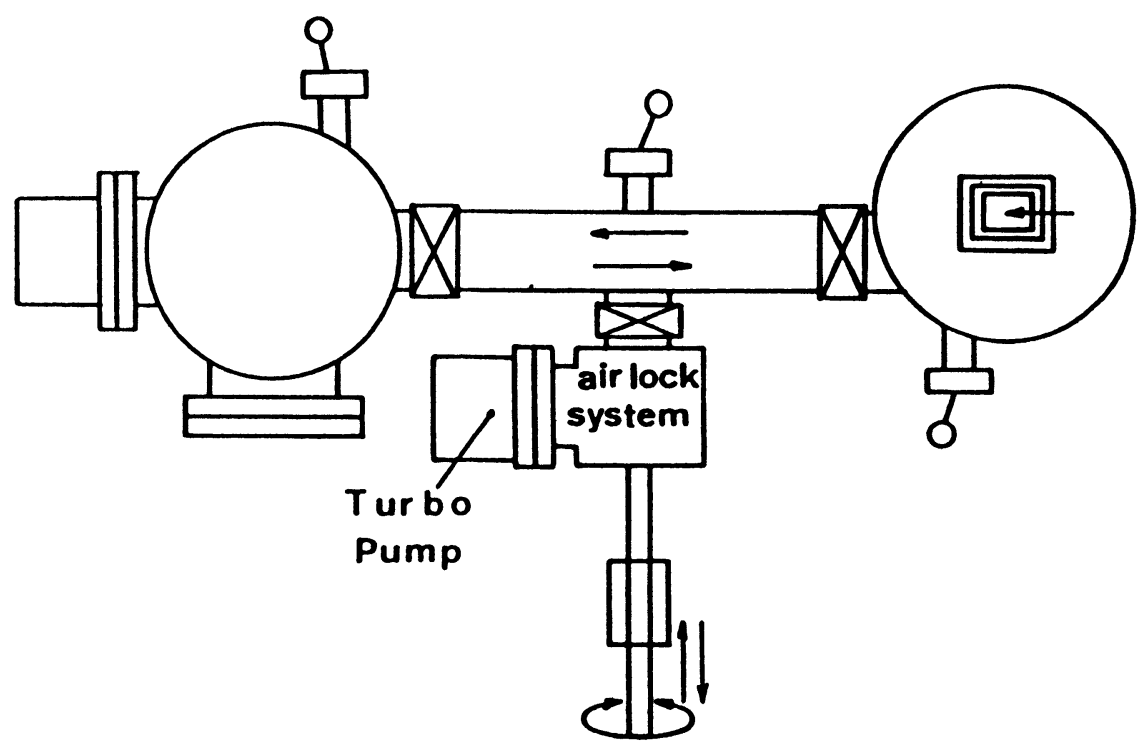

Fig. 1. - Schematic view of the experimental set-up. 


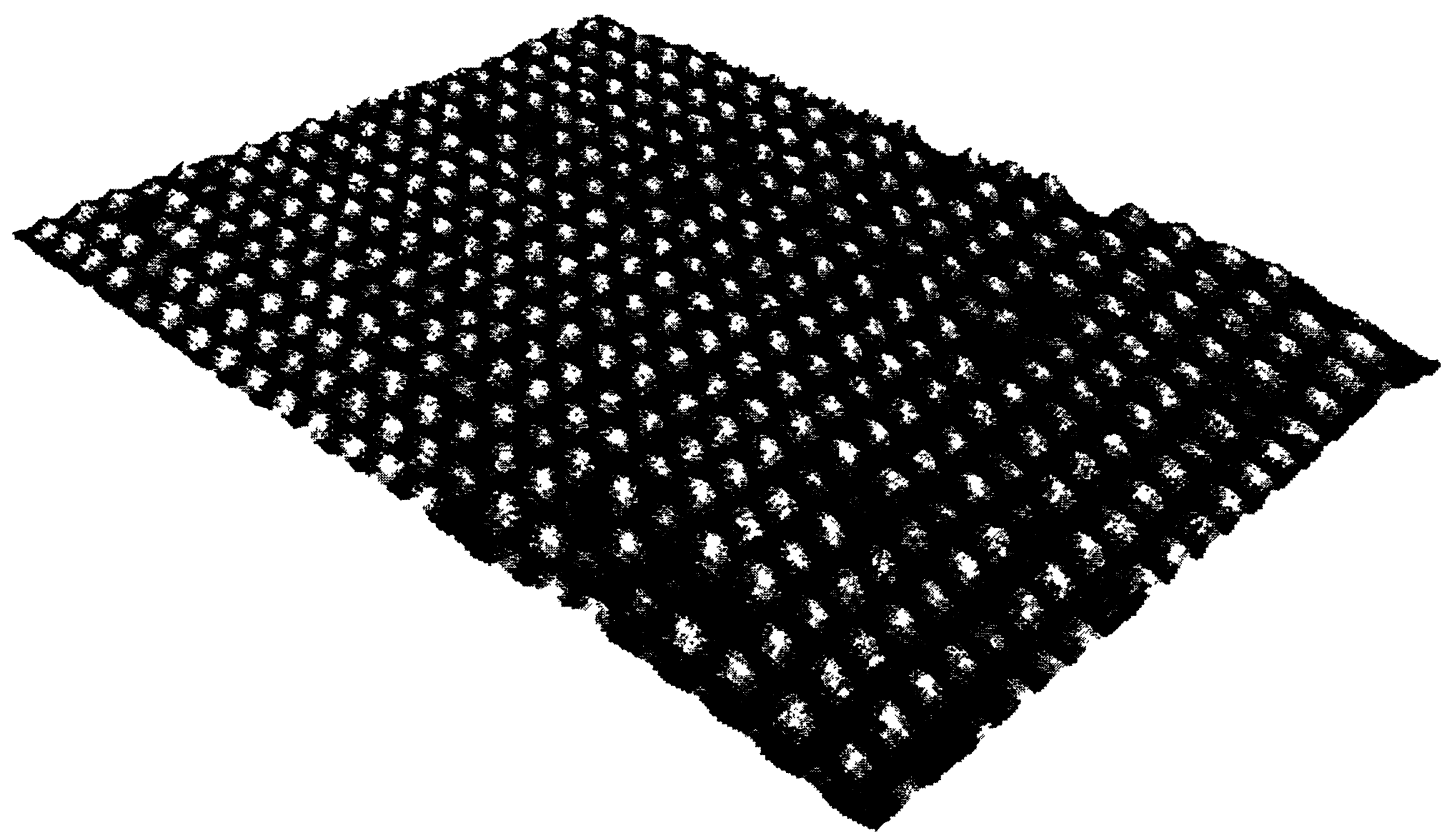

Fig. 2. - 3D perspective of a S.T.M. image of the $\mathrm{B} / \mathrm{Si}(111) \sqrt{3}$ structure (scanned area $15 \mathrm{~nm} \times 12 \mathrm{~nm}$, black to white scale $0.8 \AA$ ). White bumps are Si adatoms $0.7 \mathrm{~nm}$ apart. A few missing bumps observed at various voltages and different polarities are attributed to missing adatoms.

adatom position because of the large strains induced for such a model [5]. The more energetically favourable situation with B atoms in a sublayer substitutional position [6] thus constituting a deltadoped layer confers a remarkable stability to this substrate with interesting properties regarding metal or semiconductor epitaxy [7]. Our first data on Cu deposits on this substrate indicates that the presence of $B$ at the surface changes drastically the surface chemistry when compared to the $7 \times 7 \mathrm{Si}(111)$ substrate [8].

As a next illustration, we describe the system $\mathrm{Sn} / \mathrm{Si}(111)$.

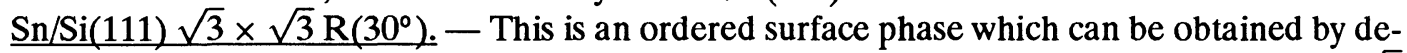
positing around 1 monolayer of Sn at RT with subsequent annealing around $600^{\circ} \mathrm{C}$ until a $\sqrt{3}$ LEED pattern is obtained. Such a system has already been observed using inverse photoemission [9].

The atomic rows of this ordered phase can be seen in real space with the 3D representation of figure 3 on a $120 \times 150 \AA^{2}$ scan window. The overall corrugation is of the order of a few atomic distances.

Figure 4 which is a zoomed out 3D representation on a larger scan window $(100 \AA)^{2}$ displays large uncovered flat parts still displaying a $7 \times 7$ reconstruction coexisting with the way and ordered structures represented in figure 3 .

This comparison really emphasizes the role that S.T.M. can play for achieving a good description of the planeity and the perfection of the surfaces. This is mainly because S.T.M. keeps the same order of magnitude in the $z$ sensitivity for orders of magnitude changes in the lateral scale.

This makes this physical tool very useful for characterization of defects, surface planeity...

This approach was systematically used to get a mesoscopic view of $\mathrm{Si}(111)$ surfaces all prepared through annealing procedures in order to get a clean surface exempt from carbon contamination 


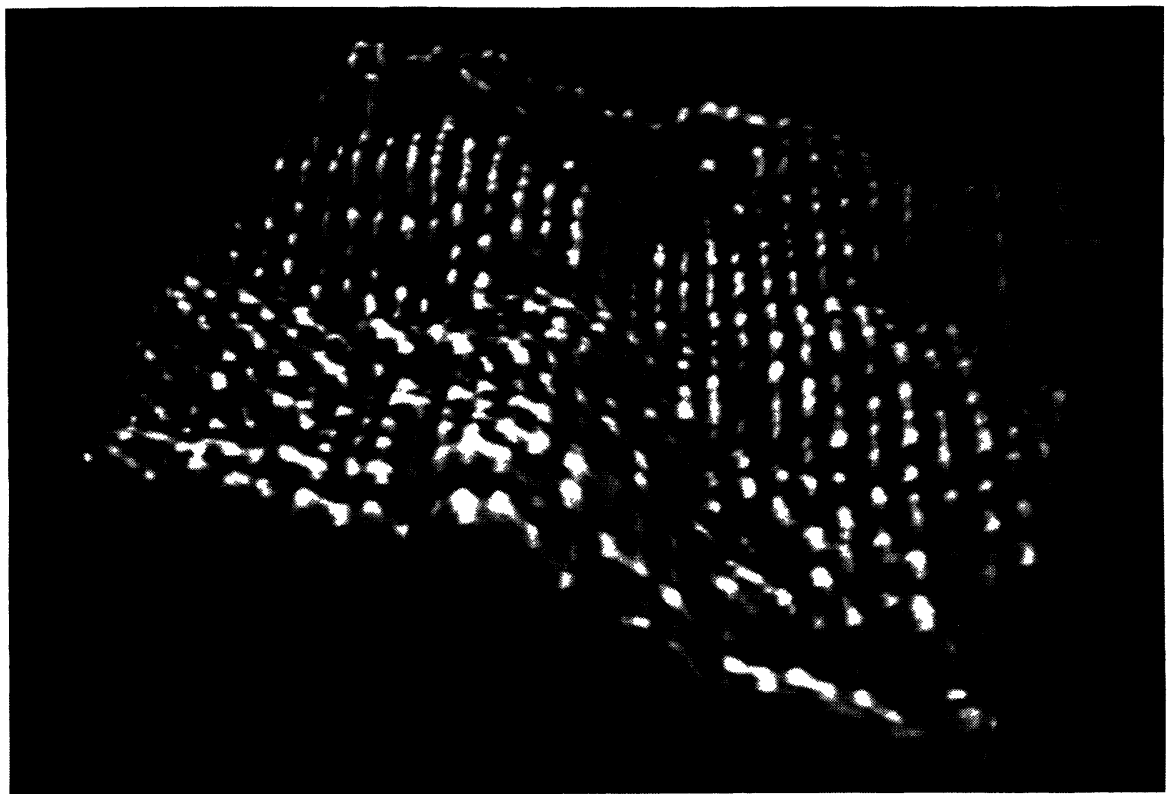

Fig. 3. - S.T.M. data registering both the surface roughness and the atomic arrangement of a $\mathrm{Sn} / \mathrm{Si}(111)$ $\sqrt{3} \times \sqrt{3} \mathrm{R}\left(30^{\circ}\right)$. The size of the image is $12 \times 15 \mathrm{~nm}^{2}$. The $z$ scale is 5 times enlarged.

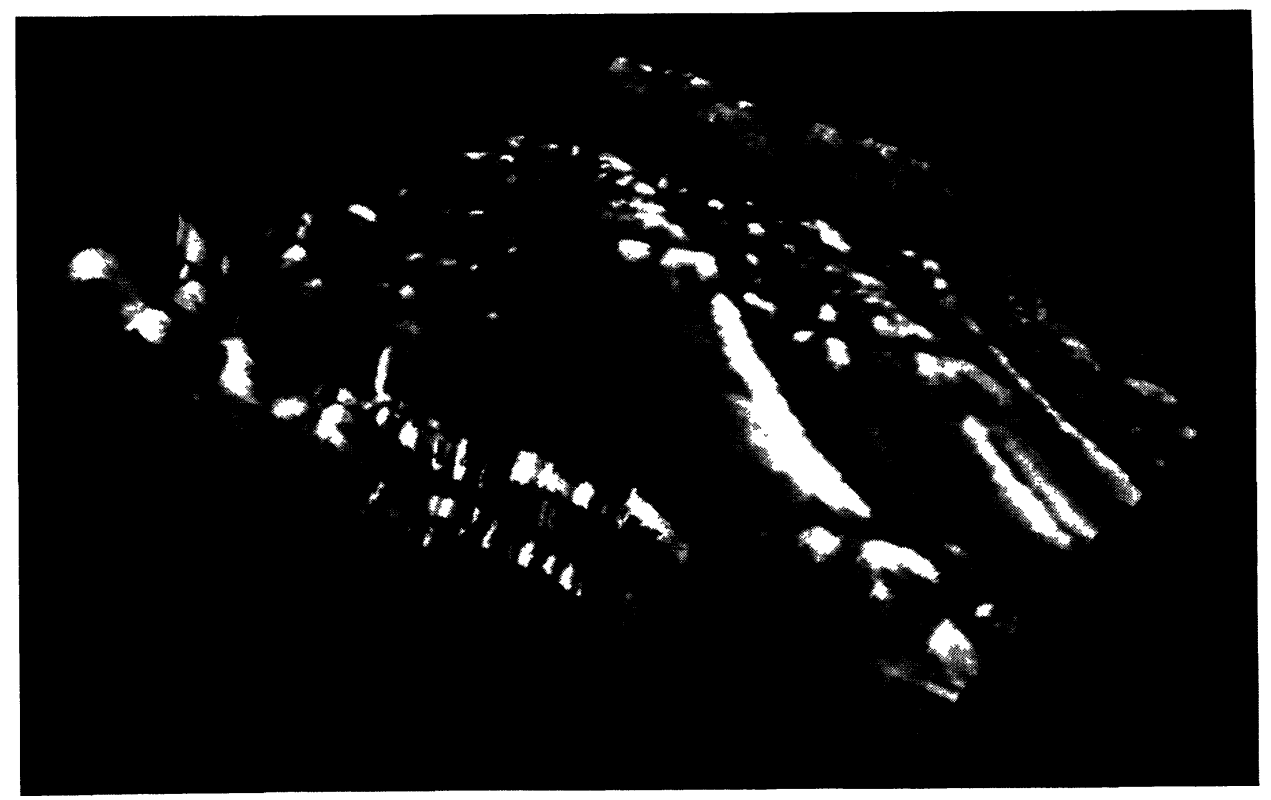

Fig. 4. - At large scale $(120 \mathrm{~nm} \times 120 \mathrm{~nm})$, it is interesting to look how the same surface looks like. The image shows steps, hilly structures and flat Sn uncovered areas. The $z$ scale is 3 times enlarged. 
and displaying a sharp $7 \times 7$ LEED pattern.

Si(111) $7 \times 7$. - The S.T.M. picture of figure 5 is a top view representation in a $500 \mathrm{~nm} \times 500 \mathrm{~nm}$ scan window of a $\mathrm{Si}(111)$ surface. The sample has been carefully disgased in UHV at $600^{\circ} \mathrm{C}$ for many hours before a series of flash annealing in UHV conditions at $1200^{\circ} \mathrm{C}$.

Terraces of a few hundred $\AA$ width separated by atomic steps along the $<1 \overline{1} 0>$ direction can be distinguished. The overall corrugation on the scanned area is $\sim 20 \AA$.

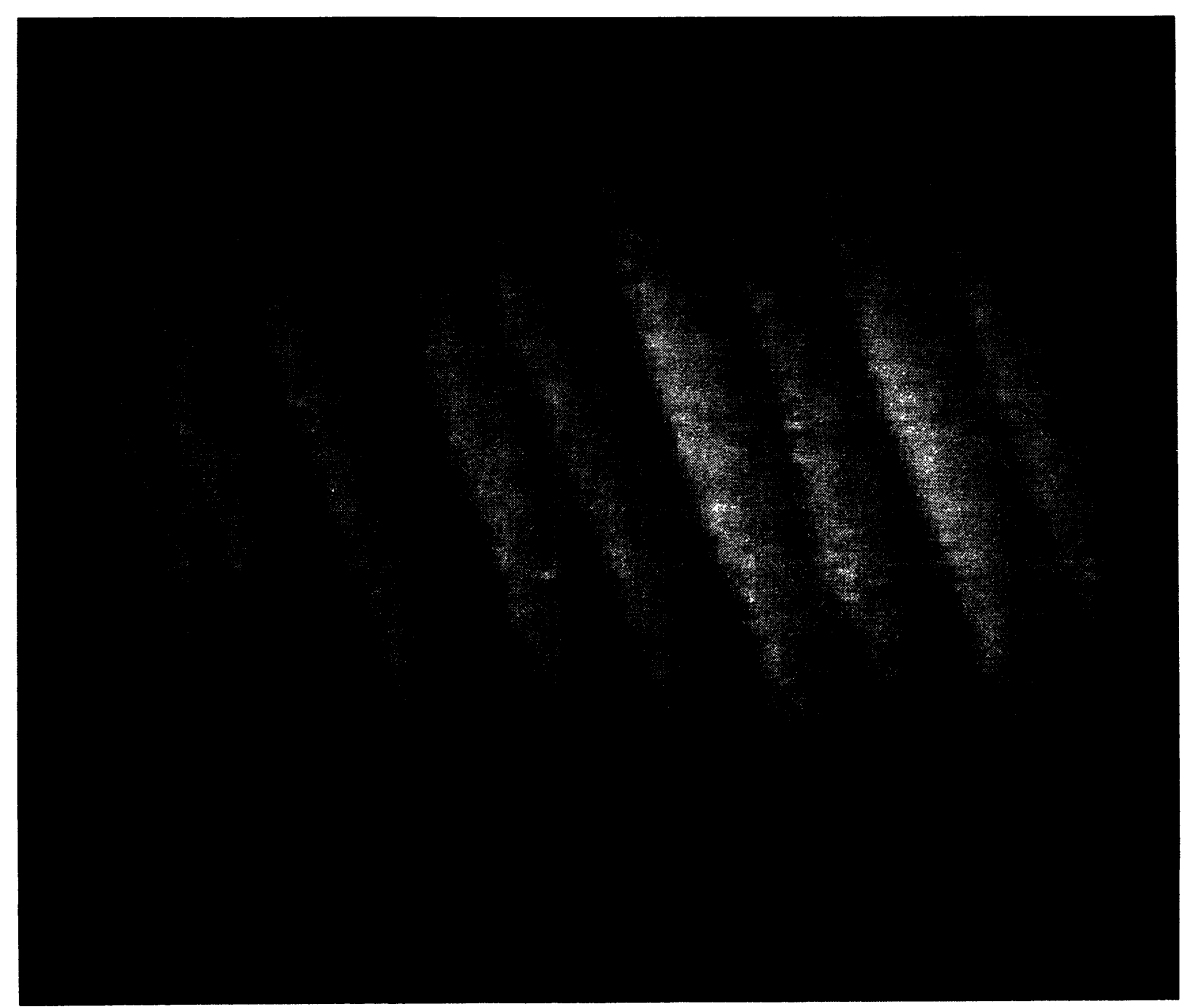

Fig. $5 .-(500 \mathrm{~nm})^{2}$ : top view representation of a $\mathrm{Si}(111)$ surface showing atomic steps separating 10 terraces.

Strain effects resulting in an assymetric clamping of the sample can produce a larger step density at the surface as shown in figure 6 . The influence of strain effects on the surface step density could thus be evidenced although no precise measurements of this correlation has been done.

This mesoscopic view provided by S.T.M. can be used for monitoring the cleaning procedure parameters when used in complementarity with averaging surface sensitive technique like LEED and Auger. The $7 \times 7 \mathrm{Si}$ substrate was used for studying silver deposits in order to perform a correlation with Ag film tiopography.

Ag/Si(111). - Silver evaporation of a 10 equivalent Ag monolayers on a Si(111) surface, similar to the one represented in figure 5, results in $\mathrm{Ag}$ clustering and the grey scale picture of figure 7 shwos that the Ag clusters are mostly aligned along the terraces of around $500 \AA$ width and that the characteristic cluster size is of the order of the terraces width. 


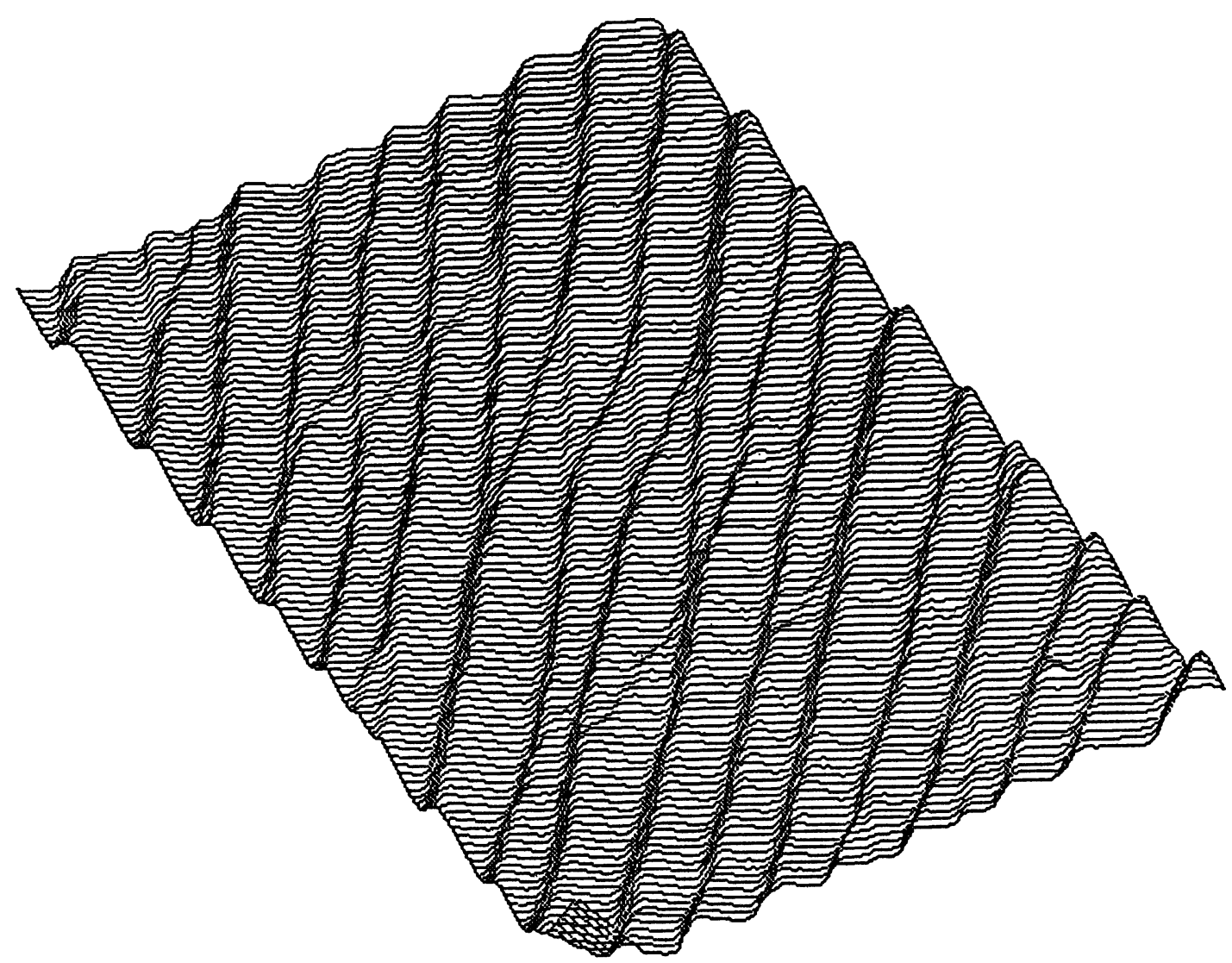

Fig. 6. - Effect of extra strain showing an increase of the number of steps on the same scan window, in a $3 \mathrm{D}$ representation of scan lines.

On a similar system at higher coverages we have studied local photon emission, as it has been proposed by Gimzewski [2] using the S.T.M. tip for local (subnanometric) injection of hot electrons. Thermalization, processes could occur radiatively and local photon can be detected. These radiative processes can be enhanced by surface roughness. It is thus important to correlate the surface morphology (clusters size...) provided by S.T.M. images at different voltages with spectroscopic photon maps. Preliminary results, not detailed here, are quite satisfactory since we could correlate the S.T.M. topography of the Ag clusters $(\sim 100 \AA)$ with the photon emission map which is strongly correlated with the Ag clusters position. The maximum intensity of light emission occurs around $3 \mathrm{eV}$. The resolution obtained for the photon map is $<100 \AA$.

\section{Conclusion.}

We have presented a few S.T.M. studies of clean or absorbate covered Si surfaces in UHV conditions. Apart from the atomic resolution which is necessary to propose structural models of ordered phases, we have shown that S.T.M. can also be used to get a mesoscopic view of the surface. Finally, we have discussed a recent development of S.T.M. for highly resolved photon emission mapping of Ag clusters on Si. 


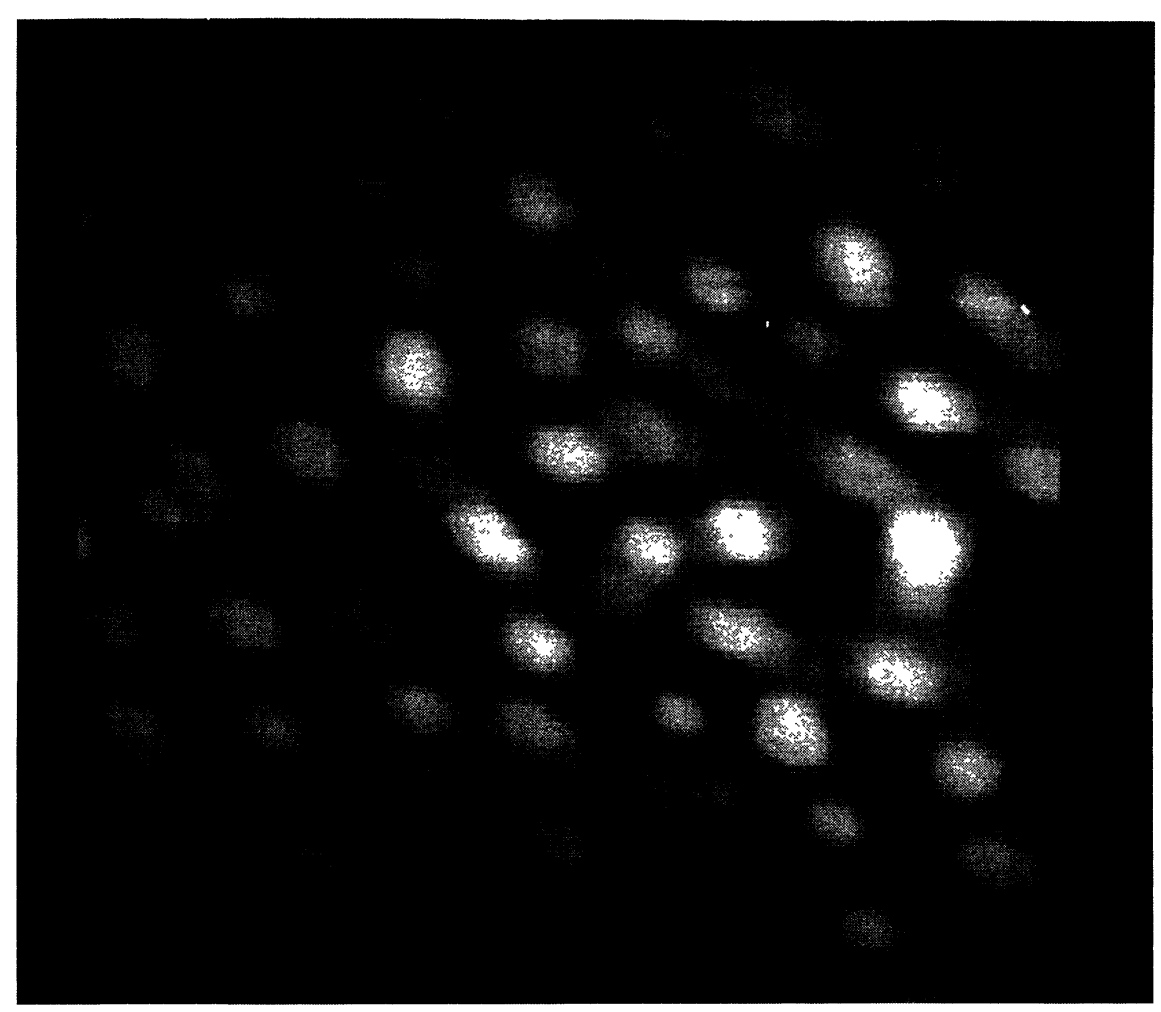

Fig. 7. - $(500 \mathrm{~nm})^{2}:$ top view image of silver clusters mostly aligned along terraces. Note the uniformity in cluster size $(\sim 500 \AA$, i.e. terrace width).

\section{Acknowledgements.}

We are grateful to J.K Gimzewski, who has suggested the preliminary photon emission cxperiment on $\mathrm{Ag} / \mathrm{Si}$, for his collaboration. We thank P. Roge who has made the first experiments on the $\mathrm{Cu}$ on the $\mathrm{B} / \mathrm{Si}(111) \sqrt{3}$ structure for communication of his data.

\section{References}

[1] Binnig G. and Rohrer H., Ilelv. Phys. Acta. 55 (1982) 726.

[2] COOMBS J.II., GimzewSKI J.K., Reinl B., SASS J.K. and ScillitTer R.R., Proc. of STM's \&8, J. Microsc. $152(1988) 325$.

[3] Dumas Ph., Thibaudau F. and Salvan F., Proccedings of STM'88, J. Microsc. 152 (1988) 751.

[4] IEAdRick R.L., Robinson I.K., Vlieg E. and Feldman L.C., Plyys. Rev. Lett. 63 (1989) 1253.

[5] Bedrossian P., Meade R.D., Mortengen K., Ciien D.M., Golovchenko J.A. and Vanderbilt D., Phys. Rev: Lett. 63 (1989) 1257.

[6] LyO I.W., KAXIRAS and AvOURIS Ph., Phys. Rev. Lett. 63 (1989) 1261.

[7] Headrick R.L., Weier B.E., BeVk J., Freer B.S., Eaglesilam D.J. and Feldmal I..C., Phys. Rev. Lett. $65(1990) 1128$.

[8] Roge P., Private communication.

[9] Kinosirta T., OitTa H., Enta Y., Yaegasi II Y., SuZuki S. and Kono S., J. Phys. Soc. Jp. Vol. 56 n $^{\circ} 11$ (1987). 